${ }^{\text {I }}$ Universidade Federal do Rio Grande do Sul (UFRGS),

Departamento de Sociologia, Brasil

sandro.ruduit@ufrgs.br

Sandro Ruduit Garcia'

\title{
PROFISSIONAIS CRIATIVOS EM CIÊNCIAS E ARTES NA CIDADE DE PORTO ALEGRE'
}

A expansão mundial de uma nova economia baseada no conhecimento e na criatividade instiga o questionamento sobre as relações entre criatividade e mercado (Comissão Europeia, 20I0; UNCTAD, 2008, 20I0; Unesco, 2013). As antigas e influentes formulações sobre as indústrias culturais denunciaram, com base na observação de sociedades industriais de massa, a impossibilidade da criação autêntica sob as condições alienantes do mercado e da tecnologia (Adorno \& Horkheimer, I985). O processo de acumulação capitalista mercantilizaria a ciência e a arte, corrompendo seus propósitos críticos. Em contraste, os conceitos derivados das formulações sobre indústrias criativas (economia criativa, classe criativa, cidade criativa) destacam a recente centralidade adquirida pela criatividade no processo econômico, em razão de mudanças na tecnologia, no direito e na sociedade (Caves, 2003; Florida, 20I I; Howkins, 20I3; Landry, 20I I). Neste caso, as instituições e regras da economia atual propiciariam mais liberdades e recursos para a expressão de talentos e habilidades de agentes individuais. Em alternativa, a proposta deste artigo é tentar oferecer uma compreensão sobre a complexidade do processo de criação de artefatos e de sua transformação em bens e serviços com valor mercantil, indagando: Que tipos de interesses e de interações sociais sustentam as atividades de criação de profissionais das ciências e das artes?

O estudo utiliza-se da abordagem da sociologia econômica, especialmente a perspectiva compreensiva e multidimensional de Max Weber (2003; 
2004; 2006). Esse approach pode oportunizar um novo ângulo de observação dessa realidade, ainda pouco investigada pela sociologia como fenômeno econômico. Estudos recentes em sociologia econômica têm apontado para os ganhos científicos em se buscar uma abordagem mais processual e relacional das atividades de criação que se traduzem em inovações nos mercados. Segundo Swedberg (2006), os estudos sobre indústrias criativas poderiam encontrar na sociologia clássica elementos para pensar a integração entre economia, arte e empreendedorismo, identificando os contornos de um "empreendedorismo cultural". Outros (Hütter et al., 20Io) chamam a atenção para o fato de que a criação da novidade, em geral, e da inovação, em particular, dependeria da combinação entre cognição, condições técnicas e constelações culturais, sendo mais adequadamente concebida como processo sociomaterial e pela cognição distribuída. O processo criativo requereria, na contribuição de Ramella (2013), a confluência de diversos fatores, como a inteligência e motivação individual, a dinâmica empresarial e setorial, os recursos e ativos territoriais, e o enraizamento social.

Neste artigo, argumento, em resumo, que as atividades de criação dos agentes dependem de uma complexa combinação entre diferentes interesses e interações sociais, exprimindo-se sempre de forma contextual. Os profissionais criativos em ciências e artes tendem a se interessar não apenas pela busca de bem-estar material, mas também pelo reconhecimento pessoal e pelo sentido ético do que fazem, criando artefatos com valor econômico e com a atribuição de significado social, aspirando à conciliação entre crescimento na carreira e qualidade de vida, e construindo trajetórias e redes de interações diversificadas que lhes permitem acessar recursos relevantes. Neste sentido, a criatividade não seria uma substância contida em mentes isoladas no laboratório ou no ateliê, nem o resultado estrito da racionalidade econômica. Esse tipo de atividade amparar-se-ia nas possibilidades de uma nova materialidade tecnológica e na legitimação de ideais, como a sustentabilidade e a qualidade de vida, demarcando lógicas de ação distintas do mundo industrial.

O pressuposto da análise é que a ação socioeconômica seria, predominantemente, movida por interesses materiais e ideais, orientando-se para a geração de utilidades (bens e serviços) e para o comportamento de outros agentes. O costume e as emoções podem, secundariamente, constituir motivos para a ação socioeconômica. Nesse sentido, os fenômenos econômicos seriam, complexa e probabilisticamente, condicionados: a) por variadas combinações (e "pesos") entre interesses materiais (racionalidade formal/ instrumental) e interesses ideais (racionalidade substantiva/de valor); b) por costumes (modo tradicional) e emoções (modo afetivo); e c) por sentidos atribuídos pelos agentes nas interações (passadas, presentes e como expectativas futuras) com outros agentes (Weber, 2004). Esse pressuposto é desenvolvido de forma integrada com formulações mais recentes em sociologia econômica - em especial, 
o enfoque relacional da chamada nova sociologia econômica - no que se refere às dimensões: a) das combinações entre interesses diversos dos agentes econômicos; e b) das atividades econômicas e arranjos de interação dos agentes.

A discussão é conduzida com base na experiência de profissionais das ciências e das artes na cidade de Porto Alegre. A cidade tem sido destacada como polo de criatividade, detendo duas importantes universidades do país, e hospedando diferentes incubadoras e parques criativos e tecnológicos. Agentes empresariais, educacionais e governamentais têm se esforçado para transformar a cidade em referência em tecnologias da informação e comunicação (TICs). Ao mesmo tempo, pode-se constatar importantes iniciativas de criação de conhecimentos e inovação requeridos para a exploração pelo país dos recursos energéticos relacionados ao pré-sal. Ademais, a cidade é reconhecida como um dos polos culturais do Mercosul, e uma das sedes da Copa do Mundo de Futebol de 2014 no Brasil, ensejando movimentações nas indústrias de comunicação, design, arquitetura, entretenimento e gastronomia. Tudo isso indica a existência de curiosas dinâmicas econômicas em torno de pequenos empreendimentos e universidades, consultorias e agências culturais, constituição e crescimento de empresas de tecnologia, envolvendo profissionais já consolidados e ingressantes nas suas carreiras em ciências e artes.

O objetivo central do artigo é, portanto, compreender e analisar condicionantes das atividades de criação de profissionais em ciências e artes na cidade de Porto Alegre, considerando-se, como dimensões de análise, as diferentes combinações de interesses que os movem e os arranjos e interações estabelecidas pelos mesmos nesse processo (além das próprias atividades de criação). O processo de amostragem orientou-se pela representatividade teórica dos dados empíricos, com a intenção de alargar a amplitude de interesses e de arranjos de interações dos agentes. Foram acessados profissionais em ciências e artes na cidade que se implicaram na geração de artefatos singulares transacionados em mercados de produtos. A partir de investigação exploratória na Internet, contataram-se casos de interesse, privilegiando-se aqueles que atuassem em universidades - centro de criatividade e trocas de conhecimentos entre profissionais de excelência - e, ao mesmo tempo, prestassem serviços para empresas, assim como em diferentes tipos de pequenos empreendimentos, observando-se significativos e variados segmentos de atuação e momentos na carreira. ${ }^{2}$

O corpus de pesquisa alcançou certa diversidade, envolvendo dados sobre a experiência de doze profissionais criativos em diferentes momentos da carreira: seis atuantes em universidades (no caso, a Universidade Federal do Rio Grande do Sul - UFRGS), sendo três seniores e três juniores; e seis atuantes em ateliês, agências, estúdios, editora e start up, sendo também três seniores e três juniores. Consideram-se seniores os profissionais cuja formação e experiência se acham consolidadas; juniores são os profissionais que aspiram 
complementação na sua formação e experiência na área de atuação. Os entrevistados pertencem a distintas profissões: quatro pesquisadores em geologia, três designers, um artesão, um músico, um profissional da publicidade, um profissional da literatura e um arquiteto. A pesquisa de campo foi realizada entre abril e novembro de 2013 , mediante entrevistas individuais semiestruturadas em profundidade que se pautaram pelas dimensões de análise acima indicadas. As entrevistas ocorreram nos locais de atuação dos profissionais, sendo gravadas, transcritas e codificadas para análise.

Seguem-se exposição de aspectos relevantes da literatura especializada; caracterização dos profissionais e produtos criativos investigados; e análise, em diferentes seções, dos interesses dos profissionais (cientistas e artistas), e dos arranjos e interações em que os entrevistados se acham envolvidos no processo de criação.

\section{CONTRIBUIÇÕES TEÓRICAS}

O fenômeno econômico em discussão neste estudo se traduz nas atividades de criação de produtos (bens e serviços) pelos profissionais de setores ligados à economia baseada no conhecimento e na criatividade, tentando melhor conhecer aspectos de alguns dos seus condicionantes. Esse debate ganhou ímpeto em torno do que se tem chamado de economia criativa. Sem entrar em detalhes sobre a construção, origens e críticas ao conceito, ${ }^{3}$ vale mencionar, sucintamente, algumas das principais contribuições ao mesmo, sublinhando a sua íntima relação com a nova economia e suas diferenças em relação ao mundo industrial de massa (Flew \& Cunningham, 2010; Pine \& Gilmore, I998).

A economia criativa consistiria, para Howkins (2013), em transações mercantis de produtos considerados criativos, em razão de sua novidade ou originalidade. A fonte de riqueza seria a criação de ideias e conteúdos simbólicos transformados em produtos no mercado, destacando que a criatividade floresceria, igualmente, nas ciências e nas artes. Tais produtos (bens e serviços) tenderiam a ser protegidos por direitos de propriedade intelectual (patentes, marcas, desenhos e, em especial, direitos autorais). ${ }^{4}$ Florida (20I I) identifica a constituição de uma classe criativa, no contexto da economia e sociedade atuais. Essa tenderia a priorizar a criatividade, a individualidade e o mérito, demarcando um ethos distinto do mundo industrial. O profissional criativo seria aquele propenso a se envolver na concepção de "produtos criativos", sendo, hoje, o principal fator de atração de empresas de alta tecnologia e, com isso, de promoção do crescimento econômico de uma região. 5 estudo em tela refere-se estritamente ao núcleo da economia criativa (atividades de concepção de artefatos).

Os processos de criação seriam expressos em diferentes fases - como a descoberta/construção de um problema, a análise da situação e identificação de alternativas e o desenvolvimento de solução original - traduzindo-se em 
termos de unicidade (ideia sem precedentes) ou de novidade (ideia com novo caráter pela combinação de ideias já existentes) (Amabile, I998; Ramella, 2013). Essas atividades podem resultar em artefatos que proporcionam realização pessoal (conceber e dar forma a um objeto), ou gerar, além disso, produtos associados a um mercado e a um aparato legal (inovação). A criatividade por si só não teria valor econômico, dependendo de diretrizes sobre leis e contratos, de convenções e normas sobre razoabilidade dos negócios e de existência de mercados (Howkins, 20I3). Em qualquer caso, as atividades no processo de criação dependeriam da combinação de habilidades dos agentes (estilos cognitivos, conhecimentos, motivação) e condições ambientais (tecnologias, normas e convenções, reconhecimento) (Amabile, I998). Mais do que isso, pode-se conjecturar sobre a criatividade como um processo sociomaterial e distribuído, envolvendo um conjunto de relações heterogêneas que, no caso de bens e serviços, perpassam o mercado (Callon, I986; Hütter et al., 2010).

Como antes mencionado, entende-se que o curso da ação socioeconômica seria movido por interesses plurais, correspondendo a um contexto de significados (Weber, 2004). Os agentes sociais não realizariam "atos gratuitos" ou desinteressados, sustentando-se sempre por uma complexa lógica das práticas sociais: “interesse é 'estar em', participar, admitir, portanto, que o jogo merece ser jogado e que os alvos engendrados no e pelo fato de jogar merecem ser perseguidos" (Bourdieu, I996: I39). Os interesses seriam as forças que movem a conduta dos agentes sociais, justificando-se a relevância sociológica em tentar compreendê-los e situá-los em contextos de ação (Swedberg, 2005), pois "os interesses são sempre socialmente construídos e podem apenas se concretizar tipicamente por meio de relações sociais" (Swedberg, 2004: 26).

Quanto aos profissionais criativos, especialistas têm discutido o peso que estes agentes atribuem às oportunidades econômicas e ao estilo de vida, na escolha de um lugar para viver e trabalhar, constatando, em maior ou menor medida, a relevância de atributos não econômicos nas suas escolhas sobre a condução das carreiras (Eikhof \& Haunschild, 2006; Florida, 20I I; Golgher, 20I I; Tremblay \& Darchen, 20II). Bendassolli e Borges-Andrade (20I I) abordam, com base numa amostra de profissionais das artes e da cultura, os significados do trabalho para esse tipo de profissional no Estado de São Paulo. Constatam que esses indivíduos atribuem grande importância ao trabalho em suas vidas, sugerindo forte comprometimento afetivo dos mesmos com suas carreiras. Isso se refletiria, sob certo aspecto, nos fatores associados a um trabalho que tenha significado para esses indivíduos, pela ordem, a possibilidade de aprender e se desenvolver pelo trabalho, sua utilidade social, a oportunidade de identificação e de expressão por meio do trabalho, autonomia, boas relações interpessoais e respeito às questões éticas. Ademais, pesquisas recentes (Novy \& Colomb, 2013) apontam envolvimentos políticos de profissionais criativos em ações coletivas, constatando, no contexto das cidades de Berlim 
e Hamburgo, crescente participação de membros da "classe criativa" (no caso, produtores culturais e trabalhadores artisticamente criativos) em movimentos sociais urbanos, tornando-se forças sociopolíticas capazes de influir no curso de políticas de desenvolvimento no âmbito local. Portanto, tais estudos ajudam a pensar sobre os interesses desses profissionais, extrapolando a estrita racionalidade econômica.

Como antes indicado, o estudo concebe o curso da ação socioeconômica não apenas como sendo movido por combinações de interesses materiais e ideais, mas também orientado, de forma relacional, para o comportamento de outros agentes, tornando-se crucial a compreensão do sentido das interações do agente com o contexto social. Afirma Ramella: "A análise da atividade, ao contrário, necessita de uma perspectiva integrada, capaz de perceber a invenção como o resultado de um processo complexo de construção social" (Ramella, 2013: 79, tradução minha). Caberia explorar o papel de processos de socialização (relações passadas) e suas implicações na construção de disposições e interesses nos indivíduos, podendo favorecer ou dificultar o desempenho em atividades de criação (Lahire, 2006). Isso leva a indagar sobre a relevância de trajetórias educacionais e profissionais como condicionantes de atividades de criação de artefatos/utilidades.

Sabe-se que os profissionais criativos teriam melhor desempenho no contexto de ampla disponibilidade de tecnologias da informação, de diversidade cognitiva e de conhecimentos, e de organizações flexíveis que lhes possibilitem liberdade e autonomia para o trabalho de invenção/inovação (relações presentes) (Powell \& Snellman, 2004). Empresas com procedimentos rígidos e burocratizados, com excessiva especialização de tarefas e com comandos autoritários, representariam condições desfavoráveis à criatividade, ao passo que empresas mais flexíveis, com reconhecimento e estímulo às novas ideias e diferentes tipos sociais, e com liberdade e autonomia de ação, tenderiam a gerar condições mais propícias ao processo de criação (Alencar, I998; Florida, 20II). As pequenas empresas tenderiam a reunir essas condições favoráveis mais facilmente do que as grandes organizações (Almeida, 20I2; Howkins, 20I3; Reis, 2008).

Ademais, o processo de criação apoiar-se-ia em redes de colaboração diversas, que extrapolam o empreendimento em que se dá forma ao produto, falando-se em novos modelos de negócios para sustentar o processo de criação e comercialização desse tipo de produtos (Almeida, 20I2). Esses modelos de negócios em setores da economia criativa estariam envolvendo não apenas esquemas de financiamento amparados em capital de risco, mas também novas estratégias de distribuição de resultados financeiros em face da gestão e distribuição de direitos de propriedade intelectual (Barrier, 20I I; Cunningham, 2008). Outros analistas (Comunian, 20I2; Glaeser, 20II) chamam a atenção para o papel desempenhado por redes de interação e sociabilidade urbana na 
construção e expressão de diferentes e novos estilos de vida e de culturas de vanguarda. A literatura aponta maiores chances nas cidades para interação arte-ciência-negócios, para oferta de lazer e cultura e para disponibilidade de infraestrutura de comunicação e tecnológica, estimulando a formulação e combinação de ideias e produtos (Eikhof \& Haunschild, 2006; Markusen \& Gadwa, 20I0)

Essas considerações brevemente referidas acima consistem em balizas e conjecturas para a análise dos dados empíricos sobre os interesses e interações sociais dos profissionais criativos em Porto Alegre feita a seguir.

\section{PROFISSIONAIS E PRODUTOS CRIATIVOS}

O perfil dos profissionais entrevistados envolve atuação em setores dinâmicos da nova economia baseada no conhecimento e na criatividade, na cidade de Porto Alegre (arquitetura, publicidade/design de música, mercado editorial, design gráfico e digital, design de moda, pesquisa e desenvolvimento, e artesanato). Esses profissionais têm alto grau de escolaridade comparativamente ao conjunto da economia e do mercado de trabalho: foram entrevistados três doutores (Geociências, Paleoclimatologia e Informática na Educação dois realizaram estágio de pós-doutorado), dois doutorandos (Engenharia da Produção e Geociências), dois mestrandos (Música e Geociências), dois graduados (Arquitetura e Jornalismo) e três profissionais com graduação incompleta (um em Nutrição e dois em Publicidade e Propaganda). Trata-se de quatro entrevistados do sexo feminino e de oito do sexo masculino, sendo seis em fase de ascensão/consolidação na carreira (júnior) e seis já consolidados e com ampla experiência profissional nas suas áreas de atuação (sênior). Como supramencionado, os entrevistados são vinculados a universidades (seis profissionais) e a ateliês, estúdios, agências e start ups (seis profissionais), na condição de servidores públicos (quatro profissionais), empreendedores (quatro profissionais), autônomos (três profissionais) e assalariados (um profissional). Todos trabalham na cidade de Porto Alegre, residindo predominantemente nesta capital (apenas um entrevistado tem residência na cidade vizinha de Canoas, na Região Metropolitana de Porto Alegre). Quase todos os profissionais entrevistados detêm algum tipo de direito de propriedade intelectual sobre artefatos produzidos (direitos autorais, patentes, marcas e desenho industrial): excepcionalmente, o artesão não detém registro de propriedade intelectual. As características e o perfil dos entrevistados são esquematizados no Quadro I. 


\begin{tabular}{|c|c|c|c|c|c|}
\hline Entrevistados & Setor & Vínculo & Organização & $\begin{array}{l}\text { Estágio da } \\
\text { Carreira }\end{array}$ & $\begin{array}{l}\text { Propriedade } \\
\text { Intelectual }\end{array}$ \\
\hline $\begin{array}{l}\text { Entrevistado I } \\
\text { (Masculino; Doutorando) }\end{array}$ & Arquitetura & $\begin{array}{l}\text { Funcionário } \\
\text { Público }\end{array}$ & Universidade & Júnior & $\begin{array}{l}\text { Direitos autorais, } \\
\text { projetos de edificações } \\
\text { e artigos }\end{array}$ \\
\hline $\begin{array}{l}\text { Entrevistado } 2 \\
\text { (Masculino; Graduação) } \\
\text { incompleta) }\end{array}$ & Publicidade & Empreendedor & $\begin{array}{l}\text { Agência de } \\
\text { publicidade }\end{array}$ & Sênior & $\begin{array}{l}\text { Direitos autorais, peças } \\
\text { publicitárias }\end{array}$ \\
\hline $\begin{array}{l}\text { Entrevistado } 3 \\
\text { (Masculino; Graduação) }\end{array}$ & $\begin{array}{l}\text { Editorial/ } \\
\text { Literatura }\end{array}$ & Empreendedor & Editora & Sênior & Livros \\
\hline $\begin{array}{l}\text { Entrevistado } 4 \\
\text { (Masculino; Graduação) }\end{array}$ & Gráfico & Empreendedor & Estúdio & Sênior & Logomarca \\
\hline $\begin{array}{l}\text { Entrevistado } 5 \\
\text { (Feminino; Doutoranda) }\end{array}$ & $P \& D$ & Autônoma & $\begin{array}{l}\text { Universidade/ } \\
\text { empresa }\end{array}$ & Júnior & $\begin{array}{l}\text { Direitos autorais } \\
\text { artigos }\end{array}$ \\
\hline $\begin{array}{l}\text { Entrevistado } 6 \\
\text { (Feminino; Mestranda) }\end{array}$ & P\&D & Autônoma & $\begin{array}{l}\text { Universidade/ } \\
\text { empresa }\end{array}$ & Júnior & $\begin{array}{l}\text { Direitos autorais } \\
\text { artigos }\end{array}$ \\
\hline $\begin{array}{l}\text { Entrevistado } 7 \\
\text { (Feminino; Doutorado) }\end{array}$ & Moda & $\begin{array}{l}\text { Funcionária } \\
\text { Pública }\end{array}$ & $\begin{array}{l}\text { Universidade/ } \\
\text { Ateliê }\end{array}$ & Sênior & $\begin{array}{l}\text { Direitos autorais, } \\
\text { coleções e artigos }\end{array}$ \\
\hline $\begin{array}{l}\text { Entrevistado } 8 \\
\text { (Masculino; Graduação } \\
\text { incompleta) }\end{array}$ & Artesanato & Autônomo & Ateliê & Júnior & NA \\
\hline $\begin{array}{l}\text { Entrevistado } 9 \\
\text { (Masculino; Mestrando) }\end{array}$ & Publicidade & $\begin{array}{l}\text { Empregado } \\
\text { Assalariado }\end{array}$ & $\begin{array}{l}\text { Agência } \\
\text { publicidade }\end{array}$ & Júnior & $\begin{array}{l}\text { Direitos peças } \\
\text { publicitárias }\end{array}$ \\
\hline $\begin{array}{l}\text { Entrevistado Io } \\
\text { (Masculino; Graduação } \\
\text { incompleta) }\end{array}$ & Gráfico & Empreendedor & & Júnior & Sinalização urbana \\
\hline $\begin{array}{l}\text { Entrevistado I I } \\
\text { (Feminino; Doutorado) }\end{array}$ & P\&D & $\begin{array}{l}\text { Funcionária } \\
\text { Pública }\end{array}$ & $\begin{array}{l}\text { Universidade/ } \\
\text { empresa }\end{array}$ & Sênior & Artigos \\
\hline $\begin{array}{l}\text { Entrevistado I } 2 \\
\text { (Masculino; Doutorado) }\end{array}$ & P\&D & $\begin{array}{l}\text { Funcionário } \\
\text { Público }\end{array}$ & Universidade & Sênior & Artigos \\
\hline
\end{tabular}

Fonte: Pesquisa de campo, Porto Alegre, abril-novembro de 2013.

Quadro I

Características dos profissionais entrevistados 
Os profissionais entrevistados criam, com apoio em TIC, diferentes tipos de produtos cuja novidade ou singularidade tende, nas convenções e diretrizes atuais sobre a transformação da criatividade em produto, a se traduzir em direitos de propriedade intelectual (Howkins, 2013). Cabe apresentar, brevemente, tais produtos. Entre os seniores em universidades, os profissionais da geologia desenvolvem, em seus respectivos laboratórios/parcerias/projetos, modelos sobre as condições das rochas que geraram e das que armazenam petróleo na camada do pré-sal da costa brasileira, resultando na produção de conhecimentos e de tecnologias mais adequados ao acesso e ao processamento da commodity (entrevistados I I e I2). O profissional do design de moda cria, entre a universidade e o ateliê, peças e coleções de vestuário voltadas para a singularidade do artefato, predominando a concepção e confecção de peças únicas que não se replicam (entrevistado 7).

O profissional da publicidade desenvolve o som de campanhas/peças de propaganda para televisão e rádio, requerendo a formulação do conceito do produto com base em linguagens de comunicação ora de âmbito nacional, ora de âmbito regional (em menor medida, o profissional também desenvolve produtos para o mercado internacional: Espanha e Mercosul) (entrevistado 2). O profissional da literatura escreve, predominantemente, romances, crônicas e narrativas históricas. Ademais, trabalha na editoração/publicação/divulgação/ circulação de obras de terceiros (entrevistado 3). O profissional do design gráfico e digital concebe artefatos de comunicação visual tais como logomarcas, embalagens, folhetos, encartes e sinalização/comunicação de lojas (entrevistado 4).

Os entrevistados juniores (em universidades e em "empresas") envolvem-se, igualmente, com artefatos que expressam novidade ou singularidade. Os profissionais da geologia têm realizado estudos e investigações sobre mapeamento sísmico e sobre condições do paleoclima, relacionados às rochas que armazenam petróleo na camada do pré-sal, permitindo acesso mais preciso ao recurso natural (entrevistados 5 e 6). O profissional da área de arquitetura tem trabalhado na criação de softwares para modelagem gráfica de edificações e na concepção de modelos e softwares aplicados à circulação e mobilidade urbana (entrevistado I). O profissional do artesanato desenvolveu, no ateliê familiar, uma técnica de tratamento e recomposição de papel que se combina com a prospecção de formas, imagens e fotografias pelas tecnologias da informação, produzindo artefatos de uso e decoração doméstica e comercial (por exemplo, porta-copos) (entrevistado 8). O profissional da música compõe, arranja e grava melodias para peças publicitárias em rádio e televisão (entrevistado 9). O profissional do design gráfico cria marcas e sistemas de sinalização urbana, como a indicação de roteiros turísticos e de transporte público (entrevistado ıo).

Cabe referir um achado de pesquisa no que tange à percepção dos entrevistados sobre direitos de propriedade intelectual. Estes são considerados relevantes entre profissionais da publicidade e literatura (entrevistados 2, $3 \mathrm{e}$ 
9). Porém, parte dos profissionais entrevistados parece atribuir relativamente pouca importância aos mesmos (em especial, no design: entrevistados I, 4, 8 e Io), percebendo-os, inclusive, em alguns casos, como uma dificuldade no processo de circulação de conhecimentos e produtos (em especial, pesquisadores: entrevistados i i e I2). Para um dos profissionais, seria um equívoco, hoje, focar a estratégia empresarial na obtenção de patentes em razão de que "a propriedade intelectual deixou de ser um grande vetor da economia" nos setores de rápida inovação (como no caso do design). Justifica sua conclusão pela percepção de que "o que vale hoje é velocidade e abrangência, ganhar adesão do usuário e ser rápido” (entrevistado Io). Cumpre notar as diferenças percebidas por alguns profissionais sobre o comportamento de empresas nacionais e estrangeiras usuárias dos conhecimentos em relação aos direitos autorais: é comum que empresas parceiras nacionais avoquem direitos e impeçam a divulgação e caracterização de resultados de pesquisa, ao passo que uma empresa parceira estrangeira não reivindica direitos sobre a produção intelectual, estimulando a publicação de resultados pelos pesquisadores (entrevistados I I e I2).

Assim, parte dos entrevistados parece, paradoxalmente, cumprir os requisitos legais sobre direitos de propriedade intelectual, em cada caso, mais como uma imposição da legislação do que como estratégia para integrar-se ou para auferir lucro nos mercados. Caberia pensar se tais achados exprimiriam a dificuldade dos agentes em manejar os condicionantes legais e burocráticos da propriedade intelectual no país (Reis, 20I2), ou expressariam uma tendência global entre certos setores econômicos e grupos sociais a eles relacionados de conceber o conhecimento e seus artefatos como bem público global que se difunde pela lógica de compartilhamento proposta na Internet (Kaul, Grunberg \& Stern, 2012).

Portanto, os profissionais das ciências e das artes selecionados para a pesquisa têm envolvimento com atividades baseadas em conhecimento e criatividade na cidade de Porto Alegre, concebendo novos artefatos (bens e serviços) e detendo, via de regra, algum tipo de direito de propriedade intelectual. De maneira geral, as atividades de criação dos artefatos, sucintamente caracterizados acima, requer uma complexa amarração entre investigação e concepção, interação com materiais e suas surpresas, e manuseio de TIC e suas possibilidades. Segundo os depoimentos colhidos nas entrevistas, o projeto e a concepção dos artefatos dependem de um ativo trabalho de pesquisa sobre recursos/insumos envolvidos e sobre necessidades/expectativas do usuário que se traduz seja em práticas de laboratório (entrevistados I, 5, 6, 7, I I e I 2), seja em estudos sobre linguagens/orientações culturais e tradições comunitárias (entrevistados 2, 3, 8 e 9), seja, ainda, em diagnóstico de demandas e tendências de mercado (entrevistados 4 e Io). Cabe, pois, saber sobre as dimensões de análise propostas na investigação. 


\section{INTERESSES PROFISSIONAIS}

Os interesses que movem os profissionais das ciências e das artes entrevistados podem ser expressos pelo exame dos significados atribuídos aos artefatos que resultam das atividades de criação, das avaliações que são feitas sobre o mercado e sua inserção na atividade econômica e sobre o local de moradia, e do grau de satisfação com trabalho e carreira.

No que se refere ao significado do produto das atividades de criação, os entrevistados tendem a revelar uma dupla preocupação em relação ao processo de prospecção, concepção e consecução dos artefatos, combinando-se a avaliação sobre a viabilidade e retorno financeiro do bem ou serviço, e a identificação de acréscimos de conhecimentos e experiências relevantes na sua carreira e de significado "social" dos artefatos (como sustentabilidade ambiental, qualidade de vida, novos conhecimentos e tecnologias, crítica e sensibilização pública sobre temas considerados importantes na agenda da comunidade ou do país). Isso se aproxima das constatações propostas em estudos recentes (Bendassolli \& Borges-Andrade, 20II; Florida, 20I I; Golgher, 20I I).

Entre os profissionais seniores, isso se expressa de diferentes formas. Os cientistas que atuam na universidade destacam não apenas o prazer da "descoberta" e da identificação do dado novo, mas também a importância da integração dos conhecimentos que estão produzindo e dos recursos humanos que estão formando ao desenvolvimento da cadeia do petróleo e gás no país (entrevistados I I e I2). O profissional sênior do design de moda que também atua na universidade busca imprimir conceitos e valores críticos ao "consumismo" nas suas atividades de criação (preço justo, sustentabilidade e contracultura de consumo). O entrevistado refere, por exemplo, o desenvolvimento de uma parceria entre seu ateliê e o banco do vestuário (da cidade de Caxias do Sul, no interior do estado). O banco do vestuário consiste em uma parceria entre indústria têxtil e artesãos daquela cidade, fornecendo resíduos de tecidos ao ateliê de Porto Alegre que retribui com a prestação de serviços de consultoria e de treinamento de artesãos envolvidos. Esses são, sob outra forma, os casos do publicitário e do designer gráfico e digital, que buscam, nos projetos de produção de campanhas e desenvolvimento de logomarcas, escapar às convenções estéticas do setor, propiciando não apenas inovações na empresa que lhes permitem acessar novos clientes e mercados, mas também o regozijo profissional e pessoal pela criação de produtos que consideram como relevantes (entrevistados 2 e 4). Ademais, o profissional da literatura e edição recusa-se a trabalhar em publicações destituídas de sentido, no contexto da sua carreira e valores, embora pudessem representar retorno financeiro. O editor/escritor deixa, por exemplo, de publicar textos considerados como do gênero autoajuda, assim como escreve seus textos com base na seleção de histórias percebidas como identificadas com a preservação da memória e da cultura locais e como de relevância ao debate público (entrevistado 3). 
Entre os profissionais juniores, pode-se identificar, a exemplo dos seniores, diversos interesses que movem suas atividades de criação. Os profissionais juniores da pesquisa em geologia destacam o prazer em pesquisar e em produzir novo conhecimento (entrevistados 5 e 6). É igualmente significativa, sobre isso, a experiência do profissional da arquitetura e professor que direcionou seus projetos e atividades para a criação e aplicação de softwares de modelagem gráfica para edificações, acreditando que a área de arquitetura perdeu sua identidade e pouco contribui na formulação de soluções para demandas da sociedade avaliadas como importantes pelo entrevistado (entrevistado I). O profissional júnior do design gráfico identifica uma nova área de atuação no setor a partir da formulação de uma concepção sobre o uso do espaço público urbano em que reflete, criticamente, sobre a "poluição visual" das cidades no país. Isso implicou a criação de novos produtos em design e sinalização urbana, que encontrou resistências no empreendimento anterior ao qual o profissional se manteve associado, partindo disso a motivação para o estabelecimento da start up atual (entrevistado Io). O profissional da música que atua em agência de publicidade refere sua orientação em integrar ao produto uma dimensão artística, empenhando-se na criação dos artefatos pela aplicação de elementos eruditos da música contemporânea (sua área de formação, pesquisa e interesse atuais) (entrevistado 9). O profissional do artesanato foca suas atividades de criação em produtos inéditos cujo significado é encontrado na observação da vida urbana cotidiana (o profissional vale-se também da fotografia), empregando a técnica de tratamento do papel e o uso de TICs. O entrevistado avalia criticamente o artesanato que se repete, seja pela produção em escala, seja pela simples reprodução da tradição (entrevistado 8).

Quanto às avaliações sobre mercado, vínculos com a vida econômica e local de moradia, os profissionais entrevistados tendem a perceber o mercado mais como um meio para veicular sua produção do que como empecilho à expressão ou distorção de suas ideias em ciências e artes. Entendem, no mais das vezes, como viável a compatibilização entre satisfação profissional e competição no mercado, embora expressem reiteradamente pressão das demandas do trabalho sobre a vida pessoal e familiar. Os entrevistados tendem a dar certa prioridade para sua qualidade de vida em face das demandas do trabalho, empenhando-se com a delimitação do tempo de trabalho e com o cultivo das relações familiares (por exemplo, almoçar com a família, acompanhar os filhos) e de atividades de lazer e entretenimento (como literatura, filmes, exposições, esportes, culinária, viagens, amigos). Desse modo, as indicações acima parecem compatíveis com a hipótese sugerida pela literatura de que profissionais criativos empenham-se em conjugar progresso e perspectivas na carreira com qualidade e estilo de vida, embora a concepção sobre o que seja isto possa variar entre contextos culturais (Eikhof \& Haunschild, 2006; Florida, 20II; Golgher, 20II; Tremblay \& Darchen, 20II). 
Os profissionais entrevistados mostram-se interessados em viver em Porto Alegre, embora alguns juniores tenham assinalado a possibilidade de viver em cidades economicamente mais dinâmicas do país - Rio de Janeiro e São Paulo (entrevistados I e 6). Identificam limitações na dimensão dos mercados em Porto Alegre, mas acreditam que seu estilo de vida seja incompatível com cidades do interior do estado, justificando sua permanência pela qualidade de vida encontrada na cidade e pela manutenção de afetos. As tecnologias de informação e comunicação favorecem as trocas à distância, tornando-se desnecessária a mudança de cidade para realizar seus projetos profissionais. Alguns entrevistados mostram-se críticos em relação ao que consideram certo conservadorismo na cultura empresarial e no mercado de Porto Alegre e do interior do estado, que criaria, em certos casos, obstáculos a produtos inovadores que são bem aceitos em outros mercados (entrevistados I, 2, 4 e Io).

Quanto ao grau de satisfação e às expectativas futuras destes profissionais, pode-se identificar, em geral, interesse em prosseguir na carreira, em ambientes organizacionais em que se percebam reconhecidos, em permanecer na cidade (em especial, seniores), e em privilegiar o que consideram como qualidade de vida. Os profissionais entrevistados tendem a expressar satisfação com a carreira e perspectivas positivas em relação às oportunidades nas suas áreas de atuação (juniores e seniores), declarando-se, em geral, satisfeitos com a carreira. É frequente entre entrevistados a percepção de expansão das chances de trabalho e carreira, destacando-se oportunidades criadas pela Copa do Mundo, pelos Jogos Olímpicos e pela exploração de petróleo na camada do pré-sal. Entendem, em geral, que os seus vínculos e organizações atuais lhes permitem desenvolver atividades significativas e prazerosas, embora o entrevistado I mostre-se crítico em relação ao ambiente encontrado na universidade.

Caberia mencionar um achado de pesquisa que se refere à propensão dos entrevistados em envolverem-se em ações coletivas e em questões percebidas como importantes para a comunidade: criação de museu, fundações para a manutenção de museu e memorial, criação de sindicato, associações profissionais e de classe, atuação em divisões de Ministérios do Governo Federal, qualificação e formação profissional, comissões de avaliação profissional, e partidos políticos. Os profissionais entrevistados expressam, em maior ou menor intensidade, interesse em atividades políticas, assumindo, em alguns casos, posições de liderança que revelam inserção no debate público e influência na vida da comunidade, aproximando-se de resultados sugeridos em outros estudos (Novy \& Colomb, 2013). Isso contraria a ideia de que profissionais criativos não se perceberiam como agentes políticos (Florida, 20I I).

Em suma, o que se tem, no conjunto dos dados, é uma orientação profissional em criar bens e serviços não apenas com valor econômico, mas também com a afirmação de significados sociais e de posições sociopolíticas dos profissionais. Isso os situa no "jogo". Outro traço comum é a diversidade de 
experiências nas trajetórias sociais, representando acúmulos de conhecimentos e de redes de interação socioprofissional que são mobilizadas nos agenciamentos envolvidos no processo de criação dos artefatos. Observa-se, entre os entrevistados, empenho em conciliar crescimento na carreira, autonomia intelectual e qualidade de vida.

\section{ARRANJOS ENTRE INTERAÇÕES SOCIAIS}

O curso de atividades de criação desenrola-se em meio a complexos arranjos entre interações sociais para o agenciamento de ideias, lugares e materiais (Callon, I986; Hütter et al., 20Io) por profissionais seniores e juniores no contexto de universidades e de empreendimentos diversos (ateliê, estúdio, agência, editora, start up).

Essas interações oferecem, em muitas situações, novas possibilidades de concepção original de bens e serviços. É oportuno notar que o projeto inicial dos artefatos é frequentemente alterado em face das exigências e surpresas oferecidas, por exemplo, pelos materiais empregados. Esse é o caso do profissional do design de moda que refere o "diálogo com os materiais, com os resíduos", identificando as diferentes "reações" dos tecidos aos tratamentos de superfície, às técnicas de colagem, à lavagem e aplicação de tintas: "cada material age de uma maneira". Os profissionais indicam surpresa diante das consequências imprevistas da complexa combinação e do trabalho de experimentação com os insumos e recursos utilizados no processo de criação.

Uma implicação disso é a percepção sobre a inadequação (e mesmo a rejeição pelos profissionais) da prescrição no processo de criação, expressa, por exemplo, na crítica, de alguns entrevistados, aos modelos de gestão baseados em programas de qualidade e produtividade com vistas à obtenção de certificação. Segundo entrevistados, esse tipo de estratégia tolhe a criação e a inovação, na medida em que estas envolvem, sempre, erro e risco. Os entrevistados mostram-se, pois, ciosos de sua autonomia intelectual e profissional.

As TICs adquirem centralidade entre os profissionais estudados não apenas porque possibilitam a integração e mobilização de capacidades distribuídas no tempo e no espaço (funções, empresas, profissionais, informações e conhecimentos), mas também porque geram novas possibilidades de ação, como novos tipos de produtos e mesmo nichos de mercado (Markusen \& Gadwa, 20Io; Powell \& Snellman, 2004). É recorrente o relato entre os profissionais seniores de que as suas áreas - design, publicidade, edição e pesquisa - foram "revolucionadas" por essas tecnologias, reduzindo o custo de equipamentos e instrumentos nas atividades de criação. Ademais, os profissionais entrevistados tendem a desenvolver habilidades de gestão e de indução à colaboração entre capacidades envolvidas no processo de criação dos seus produtos.

Podem-se identificar, ainda, aspectos relevantes quanto aos lugares, materiais e agentes associados às atividades de criação dos cientistas e artis- 
tas estudados, destacando-se o grau de complexidade implicado nas mesmas. As Tecnologias de Informação e Comunicação permitem não apenas integrar agentes e recursos em ambientes cognitivos e organizacionais diversos, mas também acelerar e vislumbrar novas possibilidades no processo de criação de bens e serviços (Almeida, 20I2; Hütter et al., 20Io). Neste caso, o domínio dessas ferramentas tecnológicas tende a significar antecipação em relação à concorrência no mercado e mesmo a prospecção de mercados inexplorados Há clara utilização não apenas de dispositivos de interação cognitiva e social a distância, mas também de trocas de ideias e conhecimentos em situações de copresença. No mais das vezes, entrevistados indicam que o trabalho em equipe e multidisciplinar requer a interação presencial no local de trabalho, em razão de que possibilita a discussão mais ágil e abrangente de problemas e o encaminhamento mais rápido de decisões. O entrevistado 9, por exemplo, refere-se à importância da linguagem corporal no trabalho musical, embora também trabalhe com colaboradores a distância; o entrevistado I refere a importância da copresença no trabalho interdisciplinar em face da necessidade de ajustamento e comunicação entre diferentes linguagens e conceitos envolvidos na criação dos artefatos. Outro traço marcante dessa complexidade é a diversidade e complementaridade de agentes envolvidos. São sobejamente apontadas as necessidades de trocas entre conhecimentos especializados em artes, negócios, tecnologia e ciências (entrevistados 2, 3, 4, 7, 8, 9 e Io) e entre disciplinas científicas e tecnológicas (entrevistados I, 5, 6, I I e I 2).

O complexo agenciamento de capacidades (tecnológicas, materiais e cognitivas) parece, pois, levar os profissionais a circular por diferentes ambientes organizacionais e sociais. Os depoimentos colhidos revelam uma complexa identificação e integração de recursos no processo de criação, requerendo do profissional a aquisição e aplicação não apenas de conhecimentos que lhes permitam conceber, ajustar e mesmo reformular projetos no curso de sua execução, mas também de habilidades de gestão e indução à cooperação entre múltiplos agentes neste percurso (Almeida, 20 2; Amabile, I998).

Essas atividades de criação sustentam-se em arranjos que podem ser expressos pela combinação entre formas organizacionais e trajetórias educacionais e profissionais dos agentes entrevistados. No que se refere à organização das atividades, constatam-se características comuns nos ambientes de criação dos artefatos. A despeito de se tratar de tipos díspares de organizações (grande universidade pública e pequenos empreendimentos), há tendências comuns nesses ambientes que se associam ao processo de criação, considerando-se a percepção dos profissionais entrevistados. Segundo os depoimentos colhidos, as atividades de criação tendem a exigir a combinação de funções e conhecimentos diversos que se desenvolve, especialmente, pelo trabalho em equipe. Isso oferece complementaridades e estímulos à criação. Outra tendência se refere à percepção de relativa autonomia e expressão no processo de 
criação, bem como de reconhecimento ao produto do trabalho (Almeida, 2012; Howkins, 2013). De modo geral, os entrevistados buscam ambientes que lhes conferem possibilidade de expressão e tomada de decisão sobre o curso das atividades de criação.

Cabe assinalar, adicionalmente, que os projetos de criação tendem a envolver algum tipo de financiamento público (exceto entrevistados 2 e 4) e, como se esperaria, atendimento a diferentes legislações, requerendo atenção às exigências do controle e a aquisição de habilidades para operar na burocracia estatal (Barrier, 20II).

Ao mesmo tempo, os profissionais entrevistados apontam diferentes tipos de dificuldades e críticas em relação às organizações em que se acham envolvidos. Por exemplo, o profissional júnior da arquitetura que atua na universidade ressente-se da falta de titulação (o entrevistado estava com doutorado em engenharia em curso no momento da entrevista) e das barreiras departamentais para a realização de atividades interdisciplinares que, a seu juízo, são cruciais na produção de conhecimentos aplicados na sua área de interesse e atuação (entrevistado I). Um dos profissionais da geologia identifica, também na universidade, o paradoxo de que a geologia experimenta momento de expansão de oportunidades de carreira e pesquisa, porém, isso tende a se concentrar em áreas relacionadas ao petróleo, em detrimentos de outras possibilidades de expansão na especialidade (entrevistado I 2). O profissional do design gráfico e digital chama a atenção para que o uso de horário flexível - outra tendência identificada entre os entrevistados - depende de relações de confiança entre os agentes envolvidos e de disciplina e capacidade de gestão do tempo, requerendo conhecimento mútuo e aprendizado (entrevistado 4). O profissional do design gráfico iniciou as atividades de sua start up em um escritório de trabalho colaborativo (co-working), em razão dos menores custos, da disponibilidade de infraestrutura adequada e da possibilidade de interação com agentes e profissionais diversos nesse tipo de ambiente. Entretanto, o alto grau de flexibilidade e a excessiva circulação e demandas por trocas profissionais tornaram, na sua avaliação, o ambiente dispersivo, reduzindo o desempenho e a produtividade de suas atividades de criação (entrevistado Io). Igualmente, o profissional do artesanato destaca a necessidade de disciplina e compromisso com o trabalho que precisam ser adquiridos pelo iniciante (entrevistado 8).

Esses registros parecem se aproximar das hipóteses sobre uma "cognição distribuída" e sobre o papel de "coletividades de pesquisa", pois as atividades de criação parecem envolver a mediação e conciliação não somente entre funções, conhecimentos, legislações e exigências diversas, mas também entre tecnologias, linguagens, instrumentos e insumos que se influenciam mutuamente (Almeida, 20I 2; Callon, I986; Hütter et al., 2010). 
Em relação às trajetórias educacionais e profissionais, os entrevistados revelam algumas convergências nos seus percursos, em especial, a formação em universidades de reconhecida qualidade e a diversidade de experiências profissionais, com passagem anterior em grandes organizações no caso dos seniores (Amabile, I998; Alencar, I998; Glaeser, 20 I I). Trata-se de experiências profissionais em diferentes organizações (assalariados em grandes e pequenas empresas, serviço público, organizações sem fins lucrativos, autônomos e empreendedores - as combinações variam conforme o caso). Essa tendência verificada de experiências plurais suscita a hipótese sobre uma combinação entre disposições para acúmulos de novas capacidades e habilidades, e a constituição de redes sociais, que são mobilizados no processo de criação dos artefatos (Comunian, 20I 2). Ao mesmo tempo, esse tipo de percurso relativiza formulações sobre capital humano que reduzem a aquisição de competências à trajetória escolar, chamando a atenção para a disposição desse tipo de profissional por buscar uma experiência plural, que representa acúmulos cognitivos e de redes sociais, refletindo-se no processo de criação.

Cabe mencionar um achado de pesquisa que se refere ao fato de que parte dos profissionais entrevistados tem origem social e familiar nas classes médias e, parte, nas classes populares, experimentando trajetória de ascensão social. O dado aproxima-se de formulações mais recentes que concebem o patrimônio de disposições adquiridas pelos indivíduos como tendências de conduta aplicadas ativamente a contextos de ação, relativizando-se dicotomias e automatismos na reprodução dos interesses e gostos de classe (Lahire, 2006). Como ilustração, pode-se mencionar o caso do publicitário cuja origem se situa no interior do Estado do Rio Grande do Sul, em família de operários sem frequência a curso superior (entrevistado 2). Diferentemente, o editor-escritor, que é natural de Porto Alegre, tem, na sua família, jornalista e poeta/cronista premiados por suas obras (entrevistado 3). Em qualquer caso, parece haver um traço comum nessas trajetórias: o apoio familiar que se pode transformar em autoestima e perseverança no percurso profissional. Isso mereceria novos estudos e aprofundamento da análise.

Como apontam especialistas (Hütter et al., 20Io; Ramella, 20I3; Swedberg, 2006), o processo de criação de inventos ou de inovações ocorreria mediante esforços individuais que, no entanto, se realizam no contexto de interações dos agentes com condições técnicas, com organizações e com sistemas sociais e territoriais. Numa palavra, interações passadas, presentes e como expectativas futuras tornam-se relevantes fontes de criatividade para os agentes nesse tipo de processo. 


\section{CONSIDERAÇÕES FINAIS}

Como inicialmente posto, o estudo apoia-se no princípio sociológico de que a ação socioeconômica seria, predominantemente, movida por interesses materiais e ideais, orientando-se para a geração de utilidades (bens e serviços) e para o comportamento de outros agentes (Weber, 2004 [I92I]). Desse prisma, aborda-se o significado das relações entre criatividade e mercado em face da ascensão de uma nova economia que se baseia na criatividade e no conhecimento, inquirindo sobre os tipos de interesses e de arranjos de interações dos agentes que sustentam as atividades de profissionais criativos.

Os profissionais criativos (em ciências e em artes) estudados na cidade escolhida envolvem-se em atividades de concepção de produtos originais, requerendo complexa amarração entre investigação e concepção (práticas de laboratório, pesquisa de linguagens e identidades comunitárias, diagnósticos de tendências e nichos de mercado), manuseio de TIC e suas possibilidades, e interação com ativos diversos. Tais profissionais se notabilizam não apenas pelo alto grau de escolaridade, mas também pelo nível de especialização nos seus conhecimentos em ciências ou em artes. Isso se combina com disposições adquiridas pela trajetória de apoio afetivo de suas famílias (seja nas classes médias, seja nas classes populares), pela formação em universidades de reconhecida qualidade e pela diversidade de experiências profissionais (Lahire, 2006).

Nas atividades de criação, os agentes tendem a conjugar a preocupação sobre a viabilidade e retorno financeiro do artefato com a identificação de experiências relevantes, em termos de acréscimos de conhecimentos ou de significado "social" do produto; mostram-se, ainda, empenhados em conciliar crescimento na carreira, autonomia intelectual e qualidade de vida, expressando certa seletividade nas suas escolhas de trabalho e na defesa de posições sociopolíticas. O agenciamento desses ativos depende de autonomia, de flexibilidade e de experiências plurais, envolvendo a mediação e conciliação entre conhecimentos, tecnologias, insumos, funções, linguagens e legislações (Hütter et al., 2010; Ramella, 2013; Swedberg, 2006).

Entre as dificuldades encontradas no processo de desenvolvimento dessa economia, merece destaque a relativa limitação do mercado para esses profissionais em Porto Alegre, que tentam superar com apoio nas comunicações e interações a distância, tendo em vista preservar a boa qualidade de vida e de trabalho que consideram ter na cidade. Cabe ressaltar que os dados obtidos referem-se ao núcleo da economia criativa, e sua interpretação requer parcimônia. Por exemplo, pouco se sabe sobre diferentes elos/setores da economia criativa, no país.

Portanto, as atividades econômicas criativas ocorreriam em meio a complexas e particulares combinações de diferentes tipos de interesses e arranjos de interações de agentes (Swedberg, 2005). Tais atividades se desenrolam 
não apenas em meio às novas condições tecnológicas de comunicação e de conhecimento, mas também no momento em que ideais em torno da sustentabilidade e da qualidade de vida ganham força. Os resultados alcançados na pesquisa (que não aspiram generalização) contribuem ao questionar não apenas a concepção sobre o desinteresse do gênio do cientista no laboratório ou do artista no ateliê, que se achariam corrompidos sob as condições de mercado, mas também relativizam as formulações que enfocam regras formais capazes de estimular respostas e induzir comportamentos reflexos de talentos individuais autointeressados.

Finalmente, cumpre notar que o fenômeno merece novas investigações desde diferentes abordagens e metodologias. As formulações sobre indústrias culturais contribuíram ao apontar a instrumentalização da ciência e da arte no mundo da produção em massa. No entanto, as recentes teses sobre indústrias criativas avançam ao chamar a atenção para as rupturas tecnológicas, econômicas e institucionais no mundo atual. O tema vem ganhando destaque no debate público e acadêmico internacional e a perspectiva multidimensional e relacional da sociologia econômica mostra-se frutífera, ao permitir compreender aspectos, mais contextuais, que escapam às formulações anteriores. $\mathrm{O}$ debate e a crítica científica poderão contribuir para melhor conhecer e precisar os contornos dessa economia e seu alcance num mundo em transformação.

Recebido em Io/05/20I4 | Aprovado em I5/04/20I5 
Sandro Ruduit Garcia é Doutor em Sociologia pela Universidade Federal do Rio Grande do Sul (UFRGS) e professor adjunto no Departamento de Sociologia e no Programa de Pós-Graduação em Sociologia desta mesma Universidade. Atua, principalmente, na área de Sociologia Econômica, dedicando-se ao estudo das indústrias criativas, da inovação e das relações entre agentes globais e locais. É autor, entre outras publicações, de "Pequena empresa inovadora e desenvolvimento: indústria naval em Rio Grande” (20I4). 


\section{NOTAS}

I O artigo baseia-se em resultados da pesquisa "Nova economia do conhecimento: agentes criativos e arranjos sócioorganizacionais em Porto Alegre", realizada com financiamento CNPq - Edital Universal. A pesquisa foi coordenada pelo autor, contando com o pesquisador Luís Fernando Santos Corrêa da Silva (UFFS), com os estudantes de pósgraduação Alexandre P. Karpowicz e Rodrigo C. Dilélio, e com a bolsista IC-Fapergs Gabriela R. de Freitas.

2 Os profissionais selecionados para estudo pertencem a setores significativos nas trocas internacionais, situando-se entre os cinco principais em termos de exportações mundiais em indústrias criativas: para dados de 2008 , os produtos de design representaram 40,87\% das exportações das indústrias criativas; em seguida, arquitetura, I 4,38\%; produtos editoriais, 8, I5\%; produtos de artesanato, $5,46 \%$; e serviço de pesquisa e desenvolvimento, $5,25 \%$ (UNCTAD, 2010).

3 O leitor encontra em Corazza (2013) uma boa resenha de alguns dos principais estudos sobre o tema. Para uma interessante apresentação e comparação de diferentes classificações de setores da economia criativa, ver Valiati (20I3). Para uma crítica ao uso da noção de economia criativa como categoria de análise, ver Alves \& Souza (2012).

4 A UNCTAD (20I0) classifica as indústrias criativas em grupos: a) Patrimônio (sítios culturais e expressões culturais tradicionais); b) Artes (visuais e performáticas); c) Mídia (publicações e audiovisual); e d) Criações funcionais (design, serviços criativos e novas mídias). As indústrias criativas seriam definidas como "os ciclos de criação, produção e distribuição de produtos e serviços que utilizam a criatividade e capital intelectual como insumos primários" (UNCTAD, 20ıо: 8). Essa classificação tem sido amplamente utilizada (inclusive no Brasil), permitindo a comparação de estudos e resultados entre diferentes países.

5 O autor identifica um "centro hipercriativo" no conjunto de ocupações da classe criativa, envolvendo profissões ligadas à computação e matemática, à arquitetura e engenharia, às ciências biológicas, naturais e sociais, à educação, treinamento e biblioteconomia, e às artes, design, entretenimento, esportes e mídia. 


\section{REFERÊNCIAS BIBLIOGRÁFICAS}

Adorno, Theodor \& Horkheimer, Max. (I985) [I944]. Dialética do esclarecimento: fragmentos filosóficos. Rio de Janeiro: Zahar.

Alencar, Eunice M. L. S. de. (I998). Promovendo um ambiente favorável à criatividade nas organizações. RAE Revista de Administração de Empresas, 38/2, p. I8-25.

Almeida, Maria I. M. de. (20I2). Criatividade contemporânea e os redesenhos das relações entre autor e obra: a exaustão do rompante criador. In: Almeida, Maria I. M. de \& Machado-Pais, José (orgs.). Criatividade, juventude e novos horizontes profissionais. Rio de Janeiro: Zahar, p. 2I-55.

Alves, Elder P. M. \& Souza, Carlos A. de C. (20I2). A economia criativa no Brasil: o capitalismo cultural brasileiro contemporâneo. Latitude, 6/2, p. I I9-I73.

Amabile, Teresa M. (I998). How to kill creativity. Harvard Business Review, 76/5, p. 76-87.

Barrier, Julien. (20I I). La science en projects: financements sur projet, autonomie professionnelle et transformations du travail des chercheurs académiques. Sociologie du Travail, 53, p. 515-536.

Bendassolli, Pedro F. \& Borges-Andrade, Jairo E. (20II). Significado do trabalho nas indústrias criativas. RAE Revista de Administração de Empresas, 5I/2, p. I43-I59.

Bourdieu, Pierre. (I996). Razões práticas: sobre a teoria da ação. Campinas: Papirus.

Callon, Michel. (I986). Some elements of a sociology of translation: domestication of the scallops and the fishermen of St Brieuc Bay. In: Law, power, action and belief: a new sociology of knowledge? Londres: Routledge, p. I96-223. Caves, Richard. (2003). Contracts between arts and commerce. Journal of Economics Perspectives, I7/2, p. 73-83.

Comunian, Roberta. (2012). Uma cidade criativa de tipo relacional: para uma cartografia das ligações em rede entre os setores público, privado e sem fins lucrativos nas indústrias criativas. Revista Crítica de Ciências Sociais, 99, p. 99-I 24 . 
Comissão Europeia. (2010). Livro verde: realizar o potencial das indústrias criativas e culturais. Bruxelas: Comissão Europeia.

Corazza, Rosana I. (2013). Criatividade, inovação e economia da cultura: abordagens multidisciplinares e ferramentas analíticas. Revista Brasileira de Inovação, I 2/I, p. 207-23I. Cunningham, Stuart D. et al. (2008). Financing creative industries in developing countries. In: Barrowclough, Diana \& Kozul-Wright, Zeljka (orgs.). Creative industries and developing countries: voice, choice and economic growth. Londres/ Nova York: Routledge, p. 65-I Io.

Eikhof, Doris R. \& Haunschild, Axel. (2006). Lifestyle meets market: bohemian entrepreneurs in creative industries. Creativity and innovation management, I5/3, p. 234-24.

Flew, Terry \& Cunningham, Stuart. (2010). Creative industries after the first decade of debate .The Information Society, 26/2, P. II3-I 23.

Florida, Richard. (20I I). A ascensão da classe criativa. Porto Alegre: L\&PM.

Glaeser, Edward. (20I I). Os centros urbanos: a maior invenção da humanidade. Rio de Janeiro: Elsevier.

Golgher, André B. (20I I). A distribuição de indivíduos qualificados nas regiões metropolitanas brasileiras: a influência do entretenimento e da diversidade populacional. Nova Economia, 2I/I, p. Io9-I34.

Howkins, John. (2013). Economia criativa. São Paulo: M. Books do Brasil.

Hütter, Michael et al. (20I0). Research program of the unit "Culture sources of newness". Discussion Paper SP III 2010405. Berlim: Wissenschaftszentrum Berlin für Sozial Forschung (WZB).

Kaul, Inge; Grunberg, Isabelle \& Stern, Marc. (2012). Bens públicos globais: cooperação internacional no século XXI. Rio de Janeiro/São Paulo: Record.

Lahire, Bernard. (2006). A cultura dos indivíduos. Porto Alegre: Artmed.

Landry, Charles. (20I I). Prefácio: cidade criativa. A história de um conceito. In: Reis, Ana Carla \& Kageyama, Peter 
(orgs.). Cidades criativas: perspectivas. São Paulo: Garimpo de Soluções.

Markusen, Ann \& Gadwa, Anne. (2010). Creative placemaking. Washington, DC: National Endowment for the Arts. Disponível em <https://www.arts.gov/publications/creative-placemaking $>$. Acesso em 29 nov. 2015.

Novy, Johannes \& Colomb, Claire. (2013). Struggling for the right to the (creative) city in Berlin and Hamburg: new urban social movements, new "spaces of hope"? International Journal of Urban and Regional Research, 35/5, p. I8I6-I838.

Pine, B. Joseph \& Gilmore, James H. (I998). Welcome to the experience economy. Harvard Business Review, s.n., jul.ago., p. 97-I05. Disponível em <https://hbr.org/ı998/o7/ welcome-to-the-experience-economy>. Acesso em 29 nov. 2015 .

Powell, Walter \& Snellman, Kaisa. (2004). The knowledge economy. Annual Review of Sociology, 30, p. I99-220.

Ramella, Francesco. (2013). Sociologia dell'innovazione economica. Bolonha: Mulino.

Reis, Ana Carla F. (20I2). Cidades criativas: da teoria à prática. São Paulo: Sesi.

Shin, Haeran \& Stevens, Quentin. (2013). How culture and economy meet in South Korea: the politics of cultural economy in culture-led urban regeneration. International Journal of Urban and Regional Research, 35/5, p. I707-I723.

Swedberg, Richard. (2006). The cultural entrepreneur and the creative industries: beginning in Viena. Journal Culture Economic, 30, p. 243-26I.

Swedberg, Richard. (2005). Max Weber e a ideia de sociologia econômica. Rio de Janeiro: Ed. UFRJ.

Swedberg, Richard. (2004). Sociologia econômica: hoje e amanhã. Tempo Social, I6/2, p. 7-34.

Tremblay, Diane \& Darchen, Sébastien. (20I I). The attraction/retention of knowledge workers and the creative city paradigm: can we plan for the talents and at what coast? The case of Montreal. Research note of the Canada Research Chair on the Socio-organizational Challenges of the Knowledge Economy. Montreal, Université du Québec, março. 
UNCTAD. (2010). Creative economy: Report 20Io. Genebra: Nações Unidas.

UNCTAD. (2008). Creative economy: Report 2008. Genebra: Nações Unidas.

UNESCO. (2013). Creative Economy Report 20I3. Special edition: widening local development pathways. Genebra: Nações Unidas.

Valiati, Leandro. (2013). Indústria criativa no Rio Grande do Sul. 2a. ed. Porto Alegre: FEE.

Weber, Max. (2004) [I92 I]. Economia e sociedade. Brasília: Ed. UnB.

Weber, Max. (2006) [I9I9]. História geral da economia. São Paulo: Centauro.

Weber, Max. (2003) [I904]. Ensaios sobre a teoria das ciências sociais. São Paulo: Centauro. 


\section{PROFISSIONAIS CRIATIVOS EM CIÊNCIAS E ARTES NA CIDADE DE PORTO ALEGRE} Resumo

$\mathrm{O}$ artigo discute as relações entre criatividade e mercado, no contexto da chamada economia criativa. O argumento é o de que as atividades de criação dos agentes dependem de uma complexa combinação entre diferentes interesses e interações sociais, exprimindo-se sempre de forma contextual. Os profissionais criativos em ciências e artes tenderiam a se interessar não apenas pela busca de bem-estar material, mas também pelo reconhecimento pessoal e pelo sentido ético do que fazem, construindo trajetórias e arranjos de interações diversificadas que lhes permitem acessar recursos relevantes. A discussão é conduzida com base na experiência de profissionais das ciências e das artes que, atuando em universidades e em pequenos empreendimentos na cidade de Porto Alegre, estão ligados a setores da nova economia baseada no conhecimento e na criatividade.

\section{CREATIVE PROFESSIONALS IN SCIENCES AND ARTS IN THE CITY OF PORTO ALEGRE, BRAZIL}

interests and social interactions, expressing themselves always in a contextual way. The creative arts and science professionals tend to be interested not only by the search for material well-being, but also for personal recognition and the ethical sense of what they do, building paths and arrangements of diverse interactions that allow them to access relevant resources. The discussion is conducted based on the experience of professionals in the arts and sciences related to sectors of the new knowledge-based and creative economy, working in universities and small businesses in the city of Porto Alegre.
Palavras-chave

Economia criativa;

Profissionais criativos;

Cientistas e artistas;

Porto Alegre;

Sociologia Econômica.

\section{Keywords}

Creative economy;

Creative professionals;

Scientists and artists;

Porto Alegre;

Economic Sociology. 